\title{
Applying Multiobjective Optimization for the Heat Supply in the Residential Sector in Budapest
}

\author{
Endre Börcsök ${ }^{* * *}$, Ágnes Gerse**, János Fülöp ${ }^{* * *}$ \\ * Óbuda University, Budapest, Hungary \\ ${ }^{* *}$ Centre for Energy Research, Hungarian Academy of Sciences, Budapest, Hungary \\ ${ }^{* * *}$ Institute for Computer Science and Control, Hungarian Academy of Sciences, Budapest, Hungary \\ borcsok.endre@energia.mta.hu, gerse.agnes@energia.mta.hu, fulop.janos@sztaki.mta.hu
}

\begin{abstract}
A multiobjective optimization methodology is presented in the context of the optimal heat supply porfolio of Budapest. The techno-economic assessment is complemented by monetizing the environmental impacts and the influence of the technology choices on human health. Among the technology options, also long-distance heating from Paks Nuclear District Heating has been considered and evaluated. The methodology is based on monthly heat demand profiles while distinguishing between three typological groups of buildings and optimizing the set and installed capacity of heating technologies for each of these groups. Our assessment shows that the resulting optimal heat supply portfolio is influenced both by the factors involved in the optimization and the types of buildings.
\end{abstract}

\section{INTRODUCTION}

In the energy sector, the supply of residential heat demand is of key importance in addition to delivering electricity to the consumers. However, the structure of heat supply systems is different from the structure of large-scale centralized electric power systems: heat supply is typically based on decentralized systems; district heating networks are mostly built in urban areas of sufficiently high heat demand density. The strong presence of seasonal patterns is also an important feature of the residential heat supply where the relative monthly differences have a high economic impact in comparison to the much lower relative monthly differences in the electricity consumption.

Going beyond a pure techno-economic assessment, it is important to consider the environmental and human health impacts, as well. In urban areas of high population density, the negative impacts on human health caused by inefficient, out-of-date, solid-fuel-based individual heating systems having low-height chimneys are by several orders of magnitude higher than in cases of district heating-based heat supply and heat pumps. The negative impacts on human health are further aggravated by the fact that polluting emissions are mostly present during the winter season at a low atmospheric mixing layer height, resulting in a higher increase in concentration.

Two different approaches have been applied to the analyzed multiobjective optimization problem involving three objectives. According to the first approach, the three objective functions were encompassed in an overall objective function by monetization and the problem was solved as a LP formulation of a simple transportation problem; while the second approach used a multiobjective optimization method.

Our research was focused on optimizing the heat supply for the residential sector of Budapest. We considered several technology alternatives to identify the optimum heat supply mix.

\section{A. Present structure of the heat supply in Budapest}

Traditionally, centralized district heating systems have an important role in the heat supply of Budapest. At the end of 2016, 258.977 residential consumers (19\% of all flats in Budapest) were connected to the district heating systems. The number of non-residential consumers is by far lower: at the end of 2016, 1.800 non-residential consumers were served by district heating [8]. As shown by Fig. 1, district heating in Budapest is provided by 9 sub-systems (1-9); in addition, there are some blocks of flats with individual heat production $(\mathrm{T})$. There are integration plans to enhance the operational flexibility of the present, fragmented subsystems by co-operation. At present, total peak heat system demand is about $1150 \mathrm{MW}$ depending on actual weather conditions, while total heat energy consumption is about 11.6 PJ/a. In recent years, total heat demand has shown a slightly decreasing tendency as a result of efforts to improve the energy efficiency of buildings [1]. Present heat sources include co-generation power plants (ranging from small power plants consisting of internal combustion engines to large main activity producers with Combined Cycle Gas Turbine technology), district heating plants, and individual boiler houses. In most of the subsystems, the share of heat from co-generation is above $50 \%$.

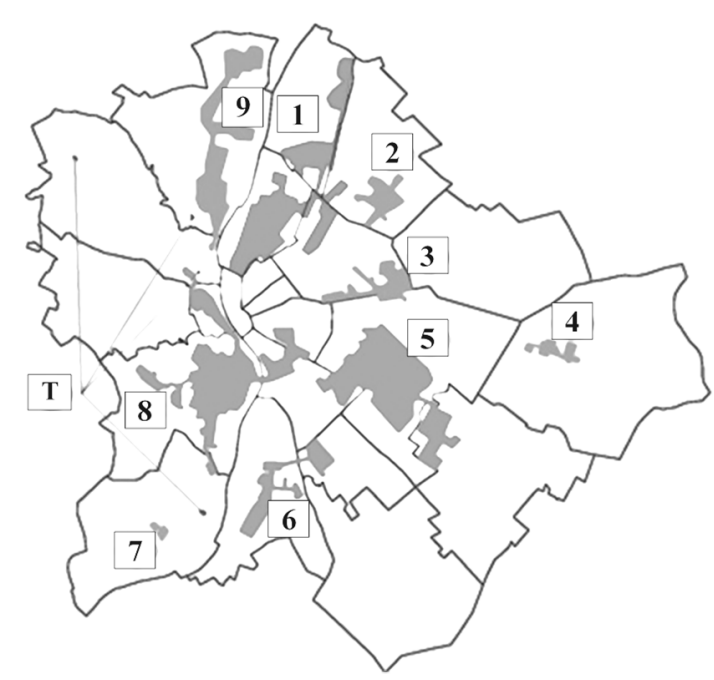

Figure 1. District heating systems in Budapest 


\section{Methodology}

In our computations, we searched for an optimal heat supply portfolio for the residential sector in Budapest under the consideration of three different aspects: economic, climate and environmental (including human health) impacts. When analyzing the economic aspect, it was necessary to distinguish between fixed and variable costs because of the large seasonality in monthly heat demand. The inclusion of the aspect related to human health in addition to the climate impact was justified by the fact that some alternatives have a high pollutant emission.

For the economic aspect, our assessment is based on the total annual cost. The objective function uses a coherent set of values of specific variable cost (given as per unit energy generated) and annualized investment cost (at a discount rate of $4 \%$ and full technical lifetime) based on national [5] and international reference databases [2], [10]. At the supply side, a wide range of technology options was considered in the assessment. Considering the economy of scale, certain alternatives were not used for the typological groups of lower heat demand density. For the technology options, some operational constraints were considered reflecting the seasonality impacts (e.g. temperature dependent variation in Coefficient of Performance of air source heat pumps), the supply-side constraints (e.g. the available amount of biomass [9], the capacity constraints of the long-distance heat supply from Paks Nuclear Power Plant).

The technology choices included the nuclear energy based district heating over a long-distance pipeline from co-generation at Paks Nuclear Power Plant. For the nuclear heating alternative, the construction of a long-distance pipeline of $144 \mathrm{~km}$ was assumed.

At the demand side, a typological approach was applied to reduce modelling complexity. Under this approach, residential buildings were classified based on heat demand density and main characteristics of heat supply, enabling the aggregate modelling of heat demand and production for each typological group that was defined. The assessment was conducted for three different building typological groups consisting of single family houses, medium-scale multi-flat buildings and large-scale multi-flat buildings [15]. For these three groups, aggregated monthly heat consumption profiles were calculated based on normalized monthly heat consumption data of a Hungarian city. This enabled the consideration of the strong seasonality in the annual heat demand profile.

For the assessment of the climate impact, the greenhouse gas emission (GHG) related to the operation was monetized, where the present, extremely low price of 5 EUR/ton of $\mathrm{CO}_{2}$ was used as a basis. For the environmental aspect, we analyzed the influence on human health, on natural and built environment. The methodology and results provided by CASES project served as a reference for monetizing the regional environmental impacts of heat production technology alternatives [11].

The search for an optimal heat supply portfolio was implemented as a transportation problem by considering the three different objectives [6], [7]. In our model, there are 28 alternatives for heat production $\left(a_{1}, \ldots, a_{28}\right)$ representing the supply points while the seasonal monthly heat demand for the three building typological groups $\left(w_{1}, \ldots, w_{12}, w_{13}, \ldots, w_{24}, w_{25}, \ldots, w_{36}\right)$ are the demand points in the model. At the supply points assigned to the heat generation alternatives, we can define the installed generation capacities $\left(p_{1}, \ldots, p_{28}\right)$; based on them, we can establish the potential monthly energy production $e_{i j}$. The value of $e_{\mathrm{ij}}$ equals to the maximum of monthly energy production by alternative $i$ in month $j: e_{i j}=h_{i j} \cdot p_{i}$. In most cases, the value of $e_{i j}$ is the product of the installed generation capacity and the monthly empirical utilization time $h_{i j}$ (about the half of the hours in each month). Monthly heat production data are represented by the values of the real variable $x_{i j}$ for each alternative that can be expressed by $p_{i j}$, the monthly "partial capacity" used: $x_{i j}=h_{i j} \cdot p_{i j}$, where $p_{i j} \leq p_{i}$ for each alternative $i$ in each month $j$.

Using the variables defined above, the standard form LP problem we have defined can be written as follows:

$$
\sum_{i \in I} \sum_{j \in J} c_{i} \cdot h_{i j} \cdot p_{i j}+\sum_{i \in I} d_{i} \cdot p_{i}=z(\min )
$$

where $\sum_{i} h_{i j} \cdot p_{i j}=w_{j}$ and $O \leq p_{i}-p_{i j}$ for each $i \in I$ and $j \in J$, furthermore $O \leq p_{i j}$ and $O \leq p_{i}$ for each $i \in I$ and $j \in J$. The optimal solution to the LP problem results in an ideal portfolio of heating alternatives. The coefficients $d_{i}$ appearing in the objective function represent the value of the fixed cost that is independent from the heat generation [14]. The coefficients $c_{i}$ express the variable cost [1] of alternative $i$, which is the part of the total cost that is proportional to the energy generation including the monetized costs of climate and environmental impacts of the production.

However, we should note that there is extensive uncertainty surrounding the monetization of climate and energy indicators. As an example, we could refer to the $\mathrm{CO}_{2}$ prices; since the introduction of the scheme of European Emission Allowances (EEA), fluctuating prices have been reached both 2 and $30 \mathrm{EUR} /$ ton of $\mathrm{CO}_{2}$ [3] We encounter the same problem when monetizing the impacts on human health [12]. In the latter case, we need to convert the years of life lost into money that raises some ethical concerns in addition to the problem of uncertainty.

In the second part of our paper, the uniform scaling of the three objectives are complemented by multiobjective optimization that enables to present its result as a sensitivity analysis, as well. Multiobjective optimization is a modelling technique used in a wide range that has a wellelaborated mathematical background; however, we rely only on some simple propositions when solving the modelling problem described in our paper [13]. When defining the multiobjective optimization problem, we multiplied the "costs" of the alternatives by weights selected from the interval $(0,1)$. In this way, each point $p\left(x_{p}, y_{p}, z_{p}\right)$ in a unit cube of edge length of 1 refers to a particular weighting of the three objectives (Fig. 2). Each point $p$ defines a LP problem.

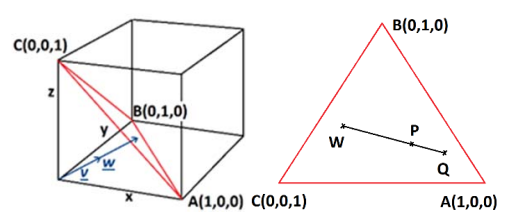

Figure 2. Space defined by the weights assigned to the three objectives 
In the optimal solution, let the value of the variable belonging to alternative $k$ be $a_{k, p}$ and let the components of the coefficients in the objective function be $\left(c_{k, x}, c_{k, y}, c_{k, z}\right)$.

Based on that, the optimal objective function corresponding to $p$ is as follows:

$$
s_{p}=\sum_{k \in I}\left(x_{p} \cdot c_{k, x} \cdot a_{k, p}+y_{p} \cdot c_{k, y} \cdot a_{k, p}+z_{p} \cdot c_{k, z} \cdot a_{k, p}\right)
$$

For a clear representation of the solutions, it is important to know that it is sufficient to examine the solutions belonging to the weight coordinates defined by the points of the cross section ABC within the cube, since if $w=\alpha \cdot v$ then $s_{w}=\alpha \cdot s_{v}$, furthermore $a_{k, v}=a_{k, w}$ for each $\bar{k} \in I$. In addition, it is important to realize that if the objective function has the same values at both ends of a line segment then it has the same value at each intermediate point.

Proposition 1:

If $s_{w}=s_{q}$ and $p=\mu \cdot \underline{w}+(1-\mu) \cdot q, \mu \in[0 ; 1]$ then $s_{w} \leq s_{p}$, in case the optimization problem is convex.

Proof:

$$
s_{p}=\sum_{k \in I}\left(x_{p} \cdot c_{k, x} \cdot a_{k, p}+y_{p} \cdot c_{k, y} \cdot a_{k, p}+z_{p} \cdot c_{k, z} \cdot a_{k, p}\right)
$$

Equation (3) can be rewritten as:

$$
\begin{aligned}
& s_{p}=\mu \cdot \sum_{k \in I}\left(x_{w} \cdot c_{k, x} \cdot a_{k, p}+y_{w} \cdot c_{k, y} \cdot a_{k, p}+z_{w} \cdot c_{k, z} \cdot a_{k, p}\right)+ \\
& +(1-\mu) \cdot \sum_{k \in I}\left(x_{q} \cdot c_{k, x} \cdot a_{k, p}+y_{q} \cdot c_{k, y} \cdot a_{k, p}+z_{q} \cdot c_{k, z} \cdot a_{k, p}\right)
\end{aligned}
$$

Therefore:

$$
s_{p}=\mu \cdot s_{w}^{\prime}+(1-\mu) \cdot s_{q}^{\prime}
$$

where $s_{w}^{\prime}$ and $s_{q}^{\prime}$ are the values of the objective function for the not necessarily optimal solutions at points $w$ and $q$. As $s_{w} \leq s_{w}^{\prime}$ and $s_{q} \leq s_{q}^{\prime}$, thus the statement $s_{w}=\mu \cdot s_{w}+(1-\mu) \cdot s_{q} \leq s_{p}$ is true.

By applying the results of the proposition above, we conducted the multiobjective assessment of the optimal heat portfolio. At first, we found the optimal solutions at points A, B and C. By dividing the $\left\{c_{k, x}, c_{k, y}, c_{k, z}\right\}_{k \in I}$ coefficients of the objective function by the values of the objective function at the optimal solutions at points $\mathrm{A}, \mathrm{B}$, and $\mathrm{C}$, a homogenization of the problem was carried out obtaining:

$$
\left\{\frac{c_{k, x}}{s_{A}}, \frac{c_{k, y}}{s_{B}}, \frac{c_{k, z}}{s_{C}}\right\}_{k \in I}
$$

After that, the solutions were established on the edges ABC.

In our study, the computations for solving both the monetized and the multiobjective problem formulation of the analyzed LP problem were completed in GAMS [4] and Excel environment, using data of monthly resolution.

\section{RESULTS}

In our study, we searched for an optimal heat supply portfolio to cover the monthly heat demand of the residential sector in Budapest that meets three objectives (economic, environmental and climate) as far as possible.

The optimization problem was solved as a transportation problem. As a first approach, we applied monetized values where the same units were applied for the monetized values of economic, environmental and climate impacts but their
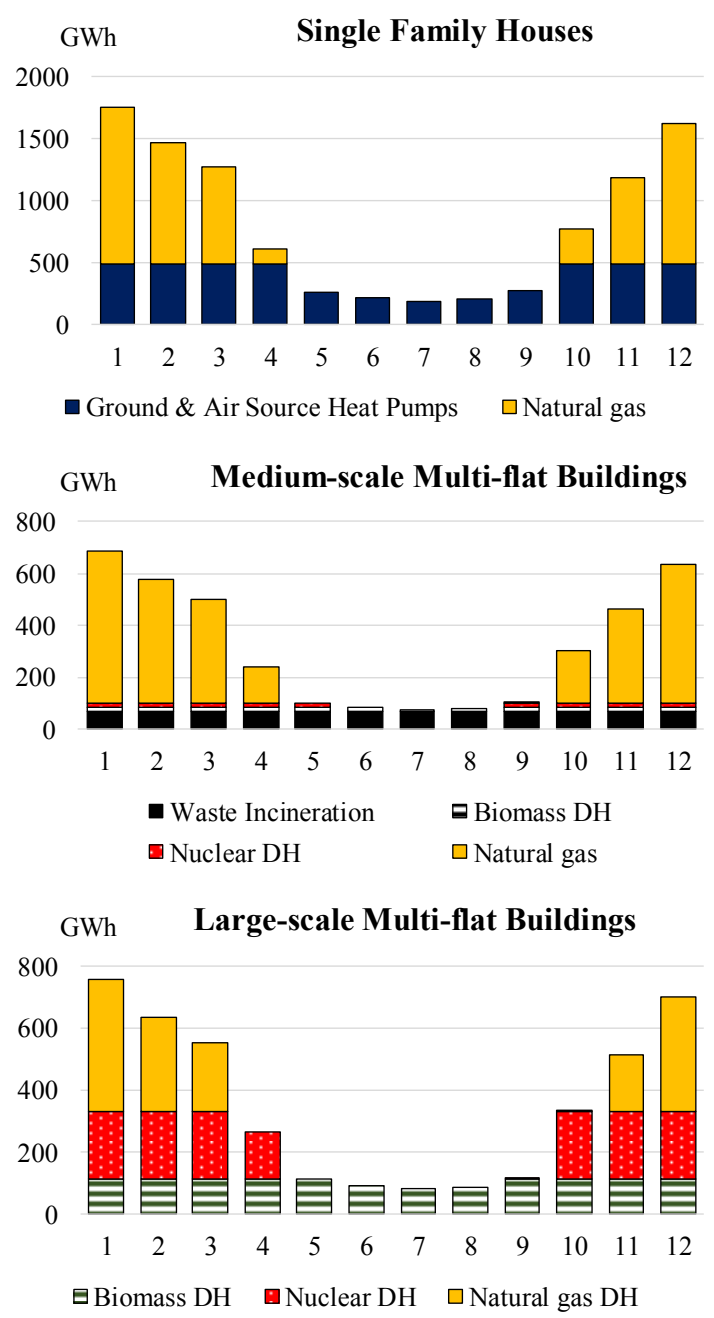

Figure 3. Optimal heat supply portfolio modelled by monetized value

scaling was substantially different. Clearly, the economic objective dominates the monetized factors while the environmental impacts come out at about one tenth when added to value of the objective function. The value of the climate impact was monetized by the value of the $\mathrm{CO}_{2}$ price of EEA. Considering that, the monetized scaling can mostly seen as an economic assessment (Fig. 3).

Our results show that the optimal heat production at single family houses mostly relies on ground and air source heat pumps while the natural gas based heating of much lower investment cost is used only to cover the peak demand in winter. In terms of several aspects, it is worth to analyze the medium-scale and large-scale multi-flat buildings together, as district heating (DH) provides the base-load heat supply in both cases. For district heating, the base-load heat is generated by municipal solid waste and biomass incineration while nuclear energy-based district heating covers the intermediate range of the heat demand. Natural gas based individual and district heating is considered to meet the peak demand in these cases, as well.

When searching for an optimal portfolio, the monetized approach is able to show the trade-off between the three objectives in a rather one-sided way. Therefore, we used a multiobjective approach to solve the problem, as well. To provide some clarity in the representation of the solutions, 

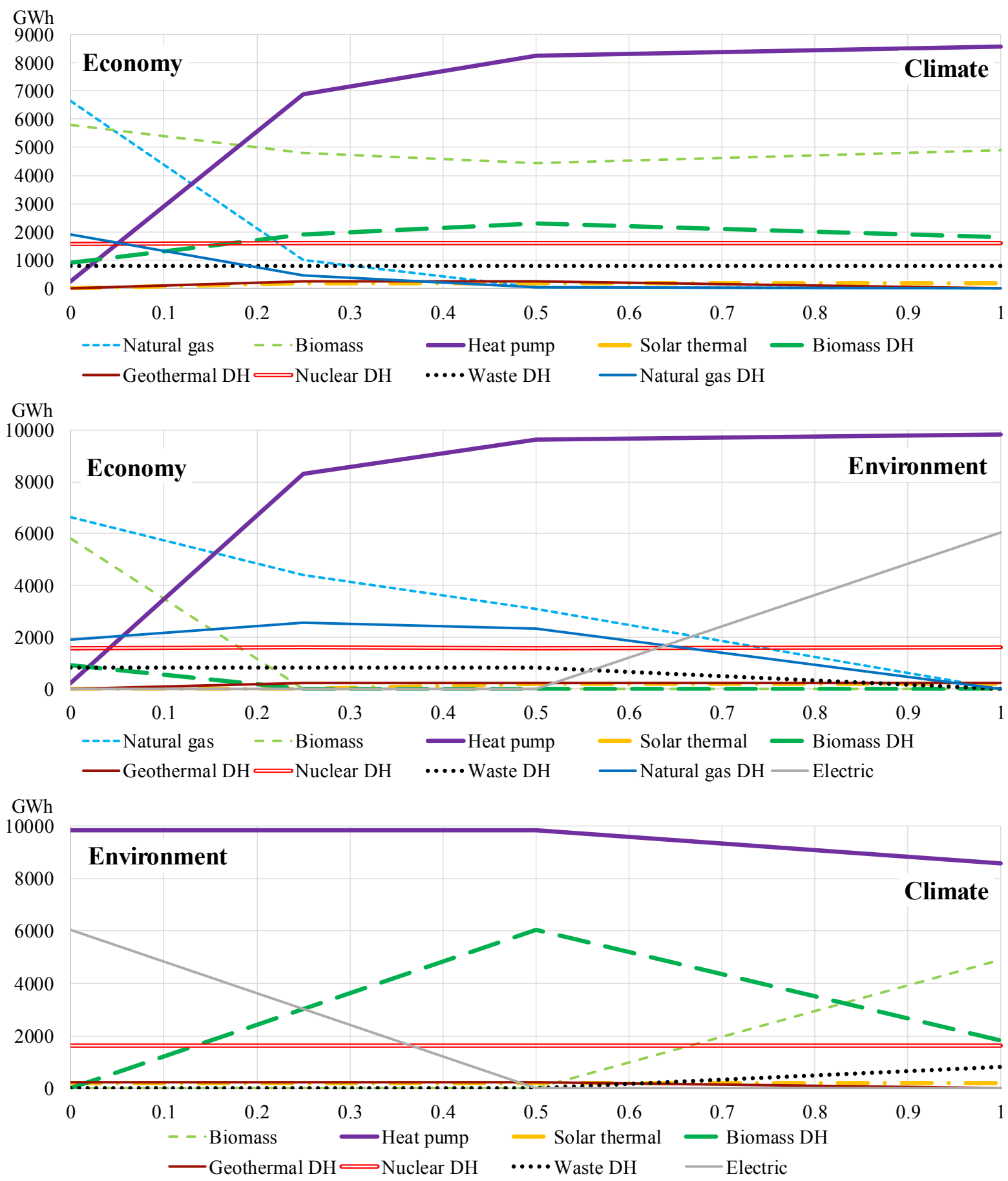

Figure 4. Optimal heat supply portfolio of Budapest based on weights, aggregated by fuel and technology under the consideration economy-climate, economy-environment and environment-climate objectives

the total annual production per fuel and technology is shown by two objectives in each case (Fig 4).

If we consider the figures computed based on objective weights as a sensitivity analysis then it can be clearly seen that the fuel and technology mix pertaining to high importance of the economic objective (weight equal to zero) are the same as in case of the monetized value. The increase in the weight factor of the climate impact can be interpreted as an increase in the $\mathrm{CO}_{2}$ prices. In the present case, an increase of 0.1 in the weight was equivalent to an increase of $150 \mathrm{EUR} / \mathrm{ton}$ of $\mathrm{CO}_{2}$. We can conclude that a
$\mathrm{CO}_{2}$ price of about $300-400 \mathrm{EUR} /$ ton of $\mathrm{CO}_{2}$ would be necessary to the substitution of natural gas by heat pumps. When highlighting the environmental impacts, there is a growing share of heat generated by heat pumps along with the reduction of the use of biomass that is substituted by electric heating (Fig. 4).

If we focus on the environmental and climate impacts, we observe that the use of natural gas is not present anymore in the optimal portfolio; its role is taken over by the heat generated by heat pumps. If preferring the climate impact to the environmental impacts then the use of electric 
heating is eliminated by the use of biomass while also the use of municipal solid waste appears in the energy mix. (Fig. 4).

\section{CONCLUSION}

In our paper, we used mathematical methods to find the optimal heat supply portfolio covering the monthly heat demand and to conduct a multiobjective assessment. Our results show the trade-off between the objectives. However, it is important to note, that our results should be interpreted in the light of high uncertainty in the individual evaluation of the alternatives according to the objectives. Therefore, the sensitivity analysis should be extended to these data, as well. Our assessment and results present the theoretical background for fuel and technology choices for residential heating while going beyond a pure techno-economic optimization. The results obtained by mathematical modelling need to be complemented by further, more detailed studies in order to identify the potential technical, operational and economic constraints.

\section{REFERENCES}

[1] B. Hartmann, E. Börcsök, V. Oláhné Groma, J. Osán, A. Talamon, Sz. Török, M. Alföldy-Boruss, Multi-criteria revision of the Hungarian Renewable Energy Utilization Action Plan - Review of the aspect of economy, Renewable and Sustainable Energy Reviews, Vol. 80, pp. 1187-1200, 2017.

[2] D. Andrews, K. A. Riekkola, E. Tzimas, J. Serpa, J. Carlsson, P. N. Garcia, I. Papaioannou, Background Report on EU-27 District Heating and Cooling Potentials, Barriers, Best Practice and Measures of Promotion, JRC Report, 2012.

[3] D. Anthoff, Report on marginal external damage costs of greenhouse gas emissions, Delivery n ${ }^{\circ} 5.4$ - RS 1b, NEEDS Project, 2007.
[4] E. R. Roshenthal, A. Brooke, D. Kendrick, A. Meeraus, R. Raman, GAMS. A User's Guide. GAMS Development Corporation, Washington, 1998.

[5] G. Büki G, J. Metzing, T. Orbán, Local Energy Supply, 2014. [in Hungarian]

[6] G. Cornuejols, J. M. Thizy, A primal approach to the simple plant location problem, in SIAM Journal on Algebraic Discrete Methods, Vol. 3, No. 4, pp. 504-510, December 1982.

[7] G. B. Dantzig, Linear Programming and Extension, Princeton University Press, 1963.

[8] Hungarian Ministry of National Development, National Building Energy Performance Strategy, Budapest, 2015.

[9] I. Barótfi. Use of biomass in Hungary. Hadtudományi közlemények, Vol. 23, pp. 271-281, 2013.

[10] J. Macadam, G. Davies, J. Cox, P. Woods, A. Turton, The Potential and Costs of District Heating Networks. A report to the Department of Energy and Climate Change, Pöyry, 2009.

[11] O. Mayer-Spohn, M. Besl, Documentation of the Life Cycle Inventory Data in CASES, CASES - Cost Assessment for Sustainable Energy Markets, Deliverable No. D6.1, October 2007.

[12] P. Preiss, V. Klotz. EcoSenseWeb V1.3 User's Manual \& Description of Updated and Extended Draft Tools for the Detailed Site-dependent Assessment of External Costs, IER, University of Stuttgart, 2008.

[13] R. E. Steuer, Multiple Criteria Optimization: Theory, Computation and Application, New York: John Wiley \& Sons, 1986.

[14] R. Porchia. Full cost estimates of the use of different energy sources, CASES - Cost Assessment for Sustainable Energy Markets, Deliverable No. D6.1, October 2007

[15] T. Csoknyai, A. Talamon, Á. Csík, M. Retek, Possible utilisation of Hungarian building typology, Magyar Épületgépészet, Vol. 59, No. 12,2010 . 
E. Börcsök et al. • Applying Multiobjective Optimization for the Heat Supply in the Residential Sector in Budapest 